\title{
ArcheoSciences
}

Revue d'archéométrie

33 (suppl.) | 2009

Mémoire du sol, espace des hommes

\section{Data Processing and Image Enhancement of GPR Surveys of Roman Villas in Austria}

Alois Hinterleitner, S. Seren, Klaus Löcker, Wolfgang Neubauer and E. Bayirli

\section{(2) OpenEdition}

12 Journals

\section{Electronic version}

URL: https://journals.openedition.org/archeosciences/1741

DOI: 10.4000/archeosciences. 1741

ISBN: 978-2-7535-1599-4

ISSN: $2104-3728$

Publisher

Presses universitaires de Rennes

\section{Printed version}

Date of publication: 30 October 2009

Number of pages: $299-302$

ISBN: 978-2-7535-0943-6

ISSN: 1960-1360

\section{Electronic reference}

Alois Hinterleitner, S. Seren, Klaus Löcker, Wolfgang Neubauer and E. Bayirli, "Data Processing and Image Enhancement of GPR Surveys of Roman Villas in Austria", ArcheoSciences [Online], 33 (suppl.) I 2009, Online since 30 October 2011, connection on 01 February 2022. URL: http://

journals.openedition.org/archeosciences/1741 ; DOI: https://doi.org/10.4000/archeosciences. 1741 


\title{
Data Processing and Image Enhancement of GPR Surveys of Roman Villas in Austria
}

\author{
A. Hinterleitner *, S. Seren* ${ }^{*}$ K. Löcker* ${ }^{*}$, W. Neubauer ${ }^{* *}$ and E. Bayirli*
}

Key words: GPR, Data processing, Image enhancement, Roman villa.

\section{INTRODUCTION}

The quality of ground penetrating radar data can suffer from many different sources of noise. Some of these sources are varying distances of the antennas to the ground due to rough surfaces, different surface conditions (e.g. compression due to tractor tracks), external electromagnetic fields and instrumental noise and instabilities (Seren, 2007). Analyses of recorded raw data and knowledge of the source of noise lead to specialised processing methods to improve the signal-to-noise ratio and to enhance the archaeological structures in depth-slice visualisations. These methods are applied to three GPR survey data-sets of Roman villas in Austria, showing clear archaeological structures but suffering from very bad surface conditions.

\section{Roman Villa HalbTurN}

The Roman villa of Halbturn (Daim, 2001) was prospected in September 2000 using a Sensor and Software PulseEKKO 1000 system with $900 \mathrm{MHz}$ antennas. An area of $100 \times 100 \mathrm{~m}$ was surveyed with a spatial resolution of 0.5 x $0.05 \mathrm{~m}$ (804201 traces). The data are very noisy because of instrument noise and instabilities of the old PulseEKKO 1000 system, and because of the rough surface due to ploughing.
Standard pre-processing methods (removal of DC-shift and depth-depending amplification (AGC)) lead to very noisy visualization (Fig. 1a, 2a). Detection and removal of erroneous traces and application of well known pre-processing methods like high-pass-filtering (removing frequencies below $450 \mathrm{MHz}$ ) (Fig. 1b, 2b) and background removal (Fig. 1c, 2c) or both (Fig. 1d, 2d) lead to much better results. Visualising only frequencies between $900 \mathrm{MHz}$ and 1800 $\mathrm{MHz}$ (Fig. 1e, 2e) enhances the visibility of the archaeological structures compared to the method in Fig. 1d. Applying a background removal filter algorithm where the length for computing the average trace is limited to $1 \mathrm{~m}$ removes a lot of striping patterns in the direction of the GPR profile by widening the archaeological structures a bit and leading to the best visualization for subsequent archaeological interpretation (Fig. 1f, 2f).

Figure 2 show the effects of the different methods described above for a part of the radargram. Fig. 2a shows the raw data. In fig. $2 b$ "horizontal" patterns are still visible after high-pass filtering and in fig $2 \mathrm{c}$ "vertical" patterns are still visible after the application of a background removal filter. In Fig $2 \mathrm{~d}$ these patterns disappear after applying both high-pass filtering and background removal. A band-pass filter $(900 \mathrm{MHz}-1800 \mathrm{MHz})$ together with a background removal filter enhance the "archaeological" structure a little (Fig. 2e). The removal of an average trace of $1 \mathrm{~m}$ length (Fig. 2f) suppresses more horizontal patterns than the bac-

* Central Institute for Meteorology and Geodynamics, Hohe Warte 38, A- 1190 Vienna, Austria. (Alois.Hinterleitner@zamg.ac.at)

** Vienna Institute for Archaeological Science, University of Vienna, Franz Klein-Gasse 1/V, A-1190 Vienna, Austria. 

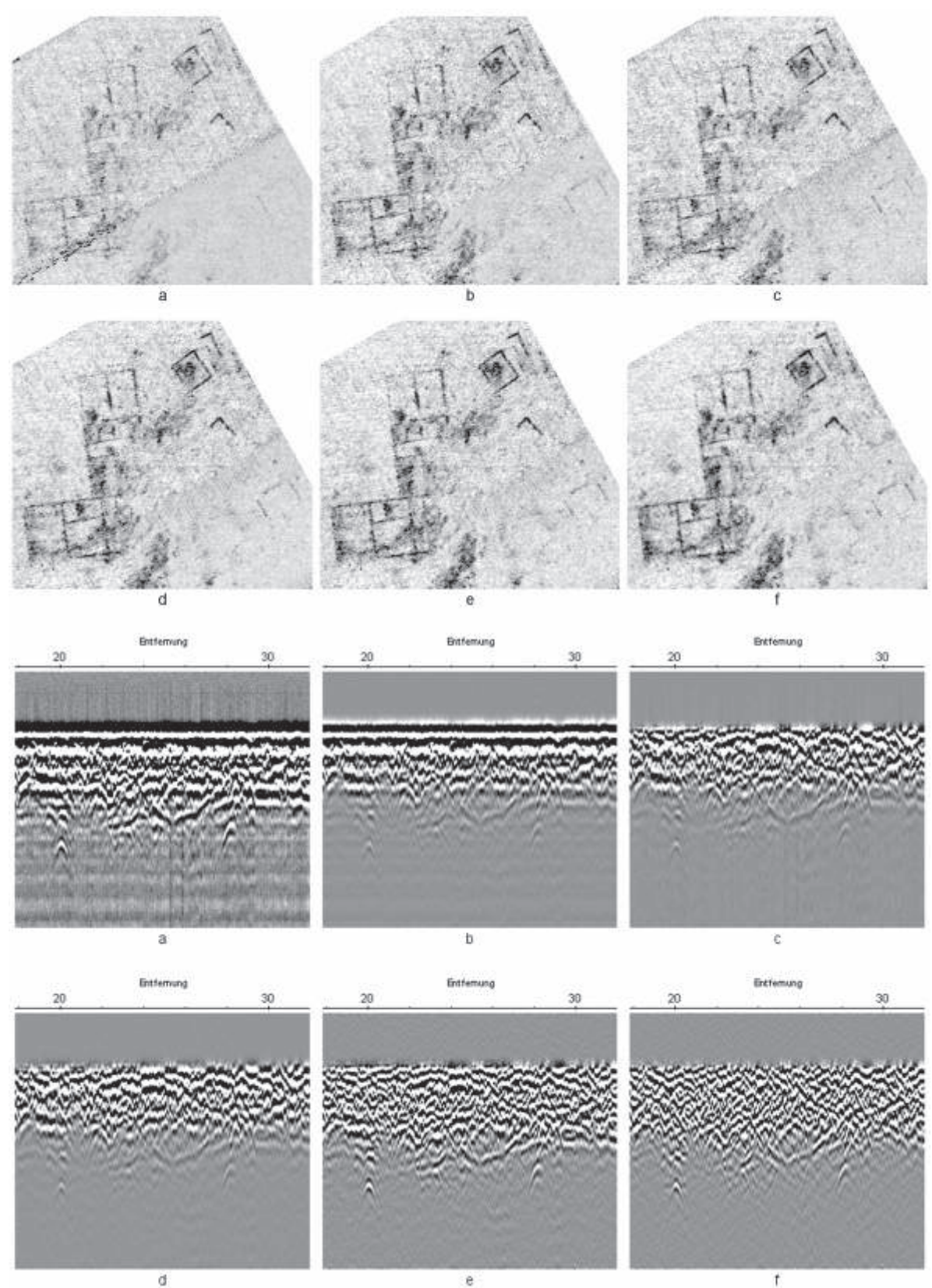

Figure 1a-f: above part of the GPR prospection of the Roman villa of Halbturn (depth slice 0.60-0.70 m) and Fig. 2a-f below. visualisation of a part of corresponding radargram (length: $14 \mathrm{~m}$; time: $30 \mathrm{~ns}$ ); a) without special pre-processing; $b$-f): removing erroneous traces; $b$ ) removing frequencies below $450 \mathrm{MHz}$; c) background removal filter; d) removing frequencies below $450 \mathrm{MHz}$ and background removal filter; e) band pass filter (900 $\mathrm{MHz}-1800 \mathrm{MHz}$ ) and background removal filter; f) band pass filter (900 $\mathrm{MHz}-1800 \mathrm{MHz}$ ) and removal of average trace of $1 \mathrm{~m}$ length. kground filter, but it also changes the hyperbolas of the archaeological structures.

\section{Roman Villa Zillingtal}

The Roman villa of Zillingtal was prospected in April 2006 and February 2008 covering an area of $14.175 \mathrm{~m}^{2}$ with a Sensor and Software Noggin System and a PulseEKKO Pro, both with $500 \mathrm{MHz}$ antennas. The survey grid was $50 \times 2.5 \mathrm{~cm}$. Both systems produce very small instrument noise, but the data suffer from tractor traces (in the middle area of Fig 3a) and ploughing areas (in the very south and east of Fig. 3a). Visualizing the data using high-pass filtering (frequencies above $250 \mathrm{MHz}$ ) and background removal filter (Fig. 3b) leads to much better results, but again a band-pass filter $(500 \mathrm{MHz}-1000 \mathrm{MHz}$ ) enhances the signal to noise ratio (Fig. 3c) and a removal of the average trace of a $1 \mathrm{~m}$ window widens the archaeological structures, but remove the line patterns produced by tractor wheels. 


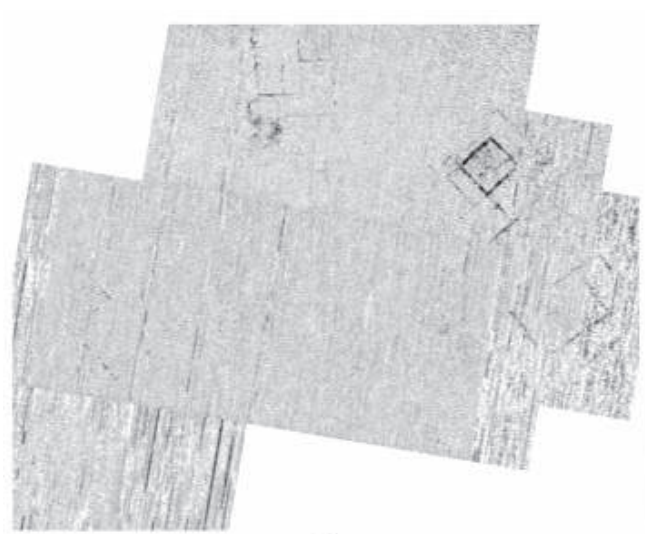

a

Figure 2: Part of the prospection of the Roman villa Zillingtal, depth slice 1,00$1,10 \mathrm{~m}$. a) without special pre-processing; b) ) removing frequencies below $225 \mathrm{MHz}$ and background removal filter; c) band-pass filtering (500-1000 MHz) and background removal filter; d) band-pass filtering (500-1000 $\mathrm{MHz}$ ) and removal of average trace of $1 \mathrm{~m}$ length.

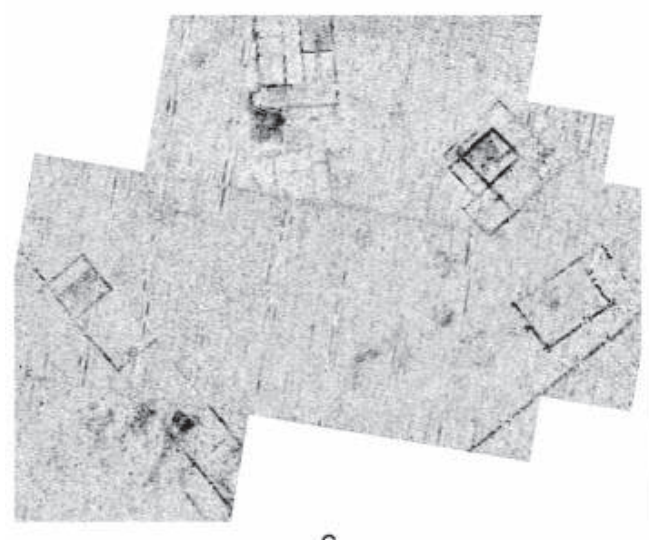

c

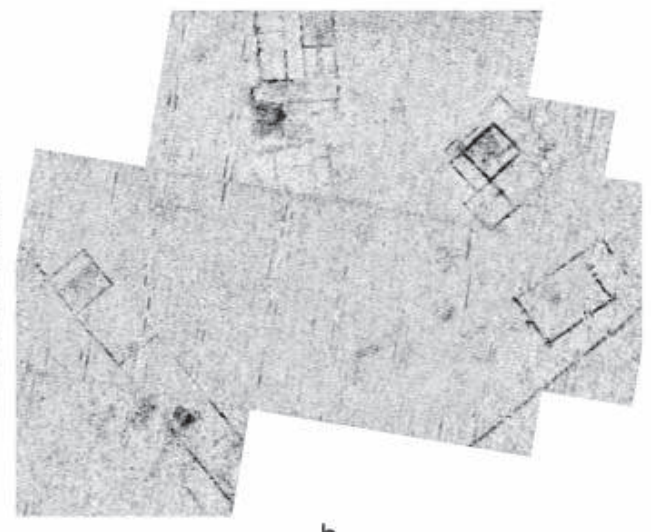

b

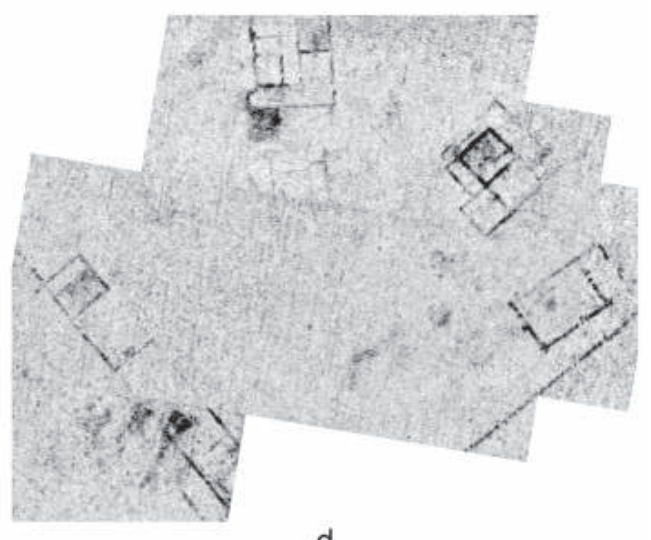

d

\section{Roman Villa Antau}

The Roman villa of Antau was prospected in April 2006 using a Noggin system and in February 2008 using a PulseEKKO Pro system, both with $250 \mathrm{MHz}$ antennas. An area of $11.500 \mathrm{~m}^{2}$ was prospected with a spatial grid of $0.5 \times 0.05 \mathrm{~m}$. These data also suffer from irregular surface conditions. Again a band-pass-filter $(500 \mathrm{MHz}-1000 \mathrm{MHz})$ together with a background removal filter produces much better visualizations of the archaeological structure compared to unfiltered data. These data show that the enhancement can vary within the depth and depends also on the instrument. While very good enhancements can be seen in all depths for the Noggin system, the PulseEKKO Pro system has few enhancements in the depth of 0.80-0.90 m, little enhancements in the depth above $(0.50-0.60 \mathrm{~m})$ and very good enhancement in the depth below $(1.10-1.20 \mathrm{~m}$ and $1.40-1.50 \mathrm{~m})$.

\section{Conclusion}

Depending on the GPR system, the antenna frequency and the surface conditions of the site, suitable band filtering and average trace removal filters with adapted length can not only improve the signal-to-noise ratio, but also enhance the visualisation of depth slices and can even make visible archaeological structures which are invisible without this special processing. Three different sites of Roman villas in Austria were prospected with different GPR systems and antenna frequencies and require suitable processing to get the best results.

\section{References}

Daim, F., Doneus, N, Neubauer, W. and Scharrer, G., 2001. The Halbturn Project: A rural Roman settlement and cemetery in Burgenland, Austria. In Doneus et al., (dir.). Archaeological Prospection, 4th Int. Conference Vienna 2001, 87-89.

Seren, S., Eder-Hinterleitner, A., Neubauer, W., Löcker, K. and Melichar, P., 2007. Extended comparison of different GPR systems and antenna configurations at the Roman site Carnuntum, Near Surface Geophysics, 5 (6): 389-394. 


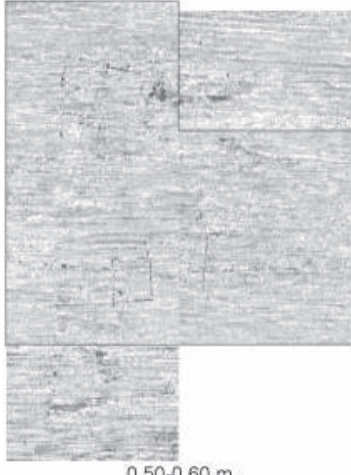

$0.50-0.60 \mathrm{~m}$

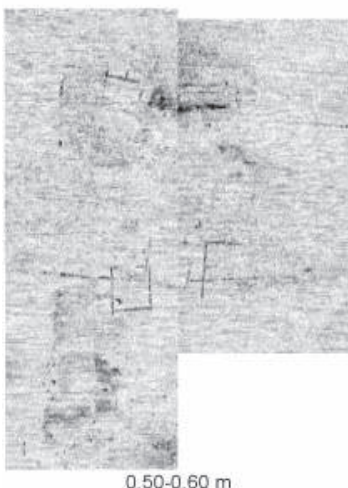

$0.50-0.60 \mathrm{~m}$

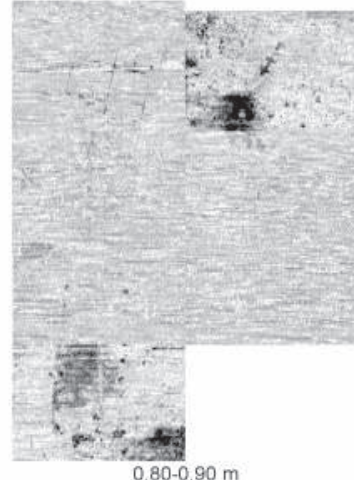

$0.80-0.90 \mathrm{~m}$

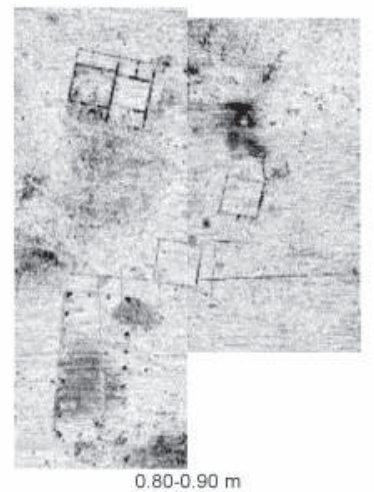

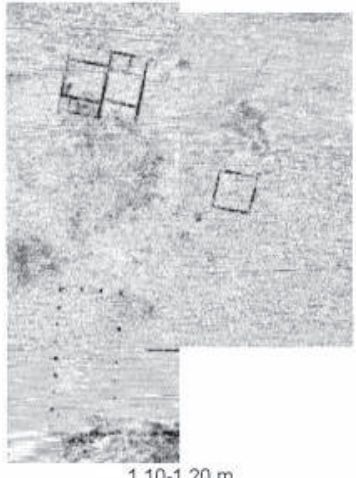

a

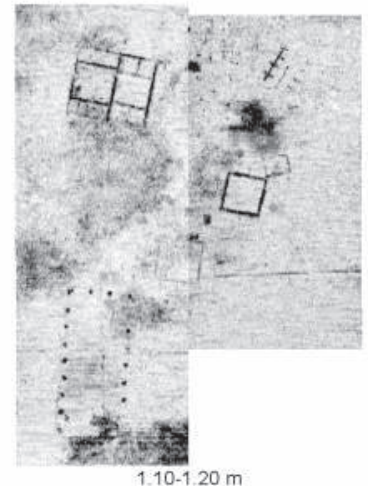

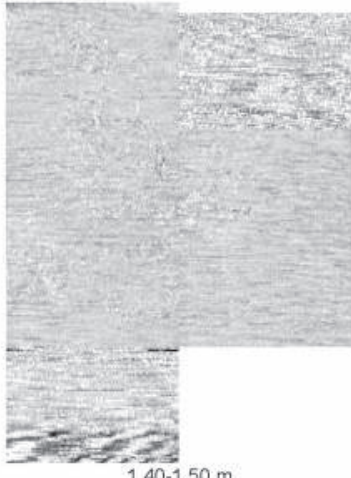

$1.40-1.50 \mathrm{~m}$

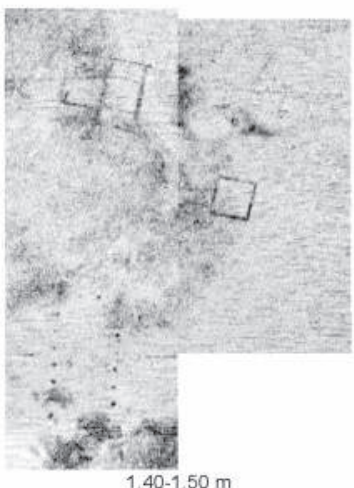

b

Figure 3: Part of the prospection of the Roman villa Zillingtal, depth slice $1.00-1.10 \mathrm{~m}$. a) without special pre-processing; b) removing frequencies below $225 \mathrm{MHz}$ and background removal filter; c) band-pass filtering $(500-1000 \mathrm{MHz})$ and background removal filter; d) band-pass filtering (500-1000 MHz) and removal of average trace of $1 \mathrm{~m}$ length. 